\title{
Lignin characteristics and density fractions of termite nests in an Amazonian rain forest-indicators of termite feeding guilds?
}

\author{
Wulf Amelung ${ }^{\mathrm{a}, *}$, Christopher Martius ${ }^{\mathrm{b}}$, Adelmar G. Bandeira ${ }^{\mathrm{c}}$, Marcos V.B. Garcia ${ }^{\mathrm{d}}$, \\ Wolfgang Zech ${ }^{\mathrm{a}}$ \\ ${ }^{a}$ Institute of Soil Science and Soil Geography, University of Bayreuth, D-95440 Bayreuth, Germany \\ ${ }^{\mathrm{b}}$ Center for Development Research (ZEF), Walter-Flex-Str. 3, 53113 Bonn, Germany \\ ${ }^{\mathrm{c}}$ Departamento de Sistemática e Ecologia, Centro de Ciências Exatas e da Natureza, Universidade Federal da Paraiba, 58059-000 João Pessoa, PB, Brazil \\ ${ }^{\mathrm{d}}$ Embrapa Amazônia Ocidental, c.p. 319, 69.011-970 Manaus, AM, Brazil
}

Received 22 February 2000; accepted 27 September 2001

\begin{abstract}
High termite abundance and diversity in rainforests results in the creation of different termite nests, which are formed from excreted food waste. The objective of this study was to elucidate the properties of nest material of common rain forest termites by analysing residues of potential food sources. In the Amazonian rain forest near Manaus, Brazil, we sampled nests of six different termite genera as well as surrounding wood, microepiphytes and soil. After a density separation into $<1.6,1.6-1.8,1.8-2.0,2.0-2.4$, and $>2.4 \mathrm{~g} \mathrm{~cm}^{-3}$ fractions, we determined the contents of $\mathrm{C}, \mathrm{N}$, and lignin-derived phenols in the samples. As particle density increased, the element and lignin concentrations decreased in all samples, the remaining lignin showed evidence of increased side-chain oxidation $(P<0.05)$. The termite nests contained 7.3-22 times more C, 14-220 more lignin-derived phenols, and 5.6-260 times more light fraction material than the surrounding surface soils $(0-10 \mathrm{~cm})$. The nests of the wood-feeding guild contained 1.2-15 times more lignin and 1.1-46 times more light material than those of the soil/wood-interface feeders. Among the different nests, the particle density increased in the order Nasutitermes sp. $<$ Cornitermes sp. $<$ Termes sp. $<$ Embiratermes sp. $<$ Anoplotermes sp. $(<$ soil $)$. In the same direction the content of lignin-derived phenols decreased from 111 to $3 \mathrm{~g} \mathrm{~kg}^{-1}$ nest material and amounted to $0.5 \mathrm{~g} \mathrm{~kg}^{-1}$ soil. The results indicated a shift from wood to soil material in the nests. Nests of Constrictotermes sp. had low lignin content despite high proportions of the light material. This indicated feeding on microepiphytes. We conclude that variations in lignin characteristics and density fractions of termite nests reflect differences in feeding guilds of the studied taxa. (C) 2002 Elsevier Science Ltd. All rights reserved.
\end{abstract}

Keywords: Soil organic matter; Lignin; Density fractions; Rain forest; Termites

\section{Introduction}

Understanding the role of termites in ecosystem functioning requires knowledge of their feeding habits. This is especially true for rain forests, where termite abundance and diversity are higher than in other ecosystems of the world (Martius, 1994; Bignell and Eggleton, 2000). The food sources of termites are diverse, varying from wood at different decomposition stages (xylophagous termites), soil organic matter (humivorous termites), or both (soil/woodinterface feeders). However, also microepiphytes growing on tree trunks (possibly Constrictotermes sp., South America), litter (leaf litter harvesters), grass, bark, fungi, and algae are consumed (Lee and Wood, 1971; Martius,

\footnotetext{
* Corresponding author. Tel.: +49-921-552146; fax: +49-921-552246.

E-mail address: wulf.amelung@uni-bayreuth.de (W. Amelung).
}

1994; Bignell and Eggleton, 2000). A food differentiation among the class of soil/wood-interface feeding termites was not detected.

Investigating the feeding habits of termites in the rainforest is difficult, due to the high variability of potential food sources and restriction in current methods of feeding identification. Ridges at the mandible surface may only roughly be used as indicators for wood or soil feeding (Deligne, 1966), and feeding experiments may not be representative (Lee and Wood, 1971; Bustamante and Martius, 1998). An identification of soil, wood, and soil/wood-interface feeders was achieved by analyses of gut contents (Sleaford et al., 1996) or tissue isotopic composition (Tayasu et al., 1997) but complications arise from the temporal heterogeneity of the gut material, differences between foraging parties and significant proportions of living microbial biomass (Varma et al., 1994; Sleaford et al., 1996). In contrast, termite 
excreta, which are used for nest construction by many species, form a reservoir of food waste that was accumulated during longer periods, especially when it is used for nest construction by the mound-building termite genera. In the savanna, the feeding of the different termite taxa was depicted from the analysis of ${ }^{13} \mathrm{C}$ natural abundance in fresh excreta (Boutton et al., 1983; Lepage et al., 1993; Spain and Redell, 1996). However, such tracing of food sources by ${ }^{13} \mathrm{C}$ analyses cannot be applied to rain forests, which lack $\mathrm{C} 3 / \mathrm{C} 4$ differences in vegetation. To identify food residues in termite nests of the soil and wood-feeding taxa of the rain forest, we needed biomarkers that specifically label the residues of soil or wood.

The density of mineral soil particles is much higher than that of wood. A density fractionation thus separates plantderived organic matter (low density) from organo-mineral complexes (including those formed by soil feeding earthworms; intermediate density) from mineral soil matter (high density) (Beudert, 1988; Christensen, 1992). Fractionating termite nests by density might therefore indicate the degree of soil feeding of a respective genus. It may not necessarily help to indicate the degree of wood-feeding, because organic matter of the light fraction may include organic sources other than wood, and because it contains labile material (Ladd et al., 1993) that might have been altered by the nest microflora. Nevertheless, termites are unable to digest lignin on a significant scale (Cookson, 1987; Pasti et al., 1990; Kuhnigk et al., 1994), and lignin in nests resists degradation (Cookson, 1992). Tracing of inert wood residues in termite nests should thus be achieved by the determination of lignin. As soils are poor in lignin, higher lignin concentrations in termite nests might indicate increased feeding on wood.

We combined the density fractionation with the chemical analyses of lignin-derived phenols for a first assessment of the composition of mound material stemming from termites belonging to the xylophagous and soil/wood-interface feeding guilds in the Amazonian rain forest. We hypothesized that the nests differ in particle density and lignin concentrations, due to a different degree of wood-feeding of the respective feeding guilds.

\section{Materials and methods}

\subsection{Samples}

In the primary rain forest near Manaus, Brazil, we sampled two nests (outer and inner wall, and nursery) of each of the termite genera and species Nasutitermes ephratae and N. costalis, Constrictotermes cavifrons, Anoplotermes banksi (all arboreal), Embiratermes aff. neotenicus, Termes fatalis (both epigeic), Cornitermes aff. weberi and Cornitermes sp. (both subterranean). Anoplotermes, Embiratermes and Termes belong to the soil/ wood-interface feeding guild, the other termites are poten- tial wood (Nasutitermes, Cornitermes) and lichen (Constrictotermes) feeders (Martius, 1994; Bignell and Eggleton, 2000; Martius et al., 2000). In addition, we took composite samples from potential food sources: surrounding topsoils in $0-10 \mathrm{~cm}$, wood, and microepiphytes (the latter only nearby nests of $C$. cavifrons). Soils are Xanthic Ferralsols (FAOUNESCO, 1997). For each genus, one respective composite soil sample was taken in the surroundings. The samples were taken with a core sampler $\left(500 \mathrm{~cm}^{3}\right)$ from each of five subsites, located in a radius of $3-5 \mathrm{~m}$ around a nest. All samples were air dried and dry-sieved $<2 \mathrm{~mm}$ prior to fractionation and chemical analyses.

\subsection{Density fractionation}

The soil and samples of the inner nest wall were separated into five density fractions: (1) $<1.6$, (2) $1.6-1.8$, (3) $1.8-$ 2.0 , (4) $2.0-2.4$, and (5) $>2.4 \mathrm{~g} \mathrm{~cm}^{-3}$. First, $15 \mathrm{~g}$ sample and $75 \mathrm{ml}$ of a sodium polytungstate solution (Sometu, Berlin) with a density of $1.6 \mathrm{~g} \mathrm{~cm}^{-3}$ was added to a $100 \mathrm{ml}$ plastic centrifugation tube. The suspension was treated with a probe type sonicator (Branson $450 \mathrm{~W}$, New York) at $20 \mathrm{~J} \mathrm{ml}^{-1}$. The ultrasonic energy input was calibrated according to North (1976); the system operated at an ultrasonic pressure ranging from 7 to $11 \mathrm{~g}$, determined as suggested by Amelung and Zech (1999). After this dispersion step, the suspension was centrifugated, and the supernatant was decanted over a glass fibre filter (Schleicher and Schuell, Germany). This yielded the fraction $<1.6 \mathrm{~g} \mathrm{~cm}^{-3}$ that was washed extensively with distilled water and freezedried. The filtered density solution was collected and used for further fractionation runs. The procedure was repeated with density solutions of $1.8,2.0$, and $2.4 \mathrm{~g} \mathrm{~cm}^{-3}$ to yield the other fractions. We used $20 \mathrm{~J} \mathrm{ml}^{-1}$ for sample dispersion every time, except for the last step $\left(2.4 \mathrm{~g} \mathrm{~cm}^{-3}\right.$ density), where we used $40 \mathrm{~J} \mathrm{ml}^{-1}$ ultrasonic energy input. At each fractionation step, centrifugation times were adjusted to the density of the respective solution, allowing particles coarser than fine clay $(0.2 \mu \mathrm{m})$ to be settled. All fractions were ground with a ball mill prior to chemical analyses.

\subsection{Chemical analyses}

For assessment of nest and food chemistry, the $\mathrm{C}$ and $\mathrm{N}$ concentrations were determined in each fraction and in the ground wood and microepiphytes, using an Elementar Vario EL C/H/N/S autoanalyzer system. Amount and degree of oxidative decomposition of lignin were estimated using alkaline $\mathrm{CuO}$ oxidation at $170{ }^{\circ} \mathrm{C}$ for $2 \mathrm{~h}$ (Hedges and Ertel, 1982), using the modifications of Kögel (1986) and Amelung et al. (1997). Liquid-liquid extraction was replaced by a solid-phase extraction of the phenols using octadecyl-bonded silica (Macheray and Nagel, Germany). Phenolic oxidation products were dissolved and derivatized with a $1: 2(\mathrm{v} / \mathrm{v})$ mixture of pyridine and $\mathrm{N}, \mathrm{O}$-bis(trimethylsilyl)trifluoroacetamide (Fluka), separated by capillary gas chromatography (HP 5 fused silica column, $25 \mathrm{~m}, 0.2 \mathrm{~mm}$ 


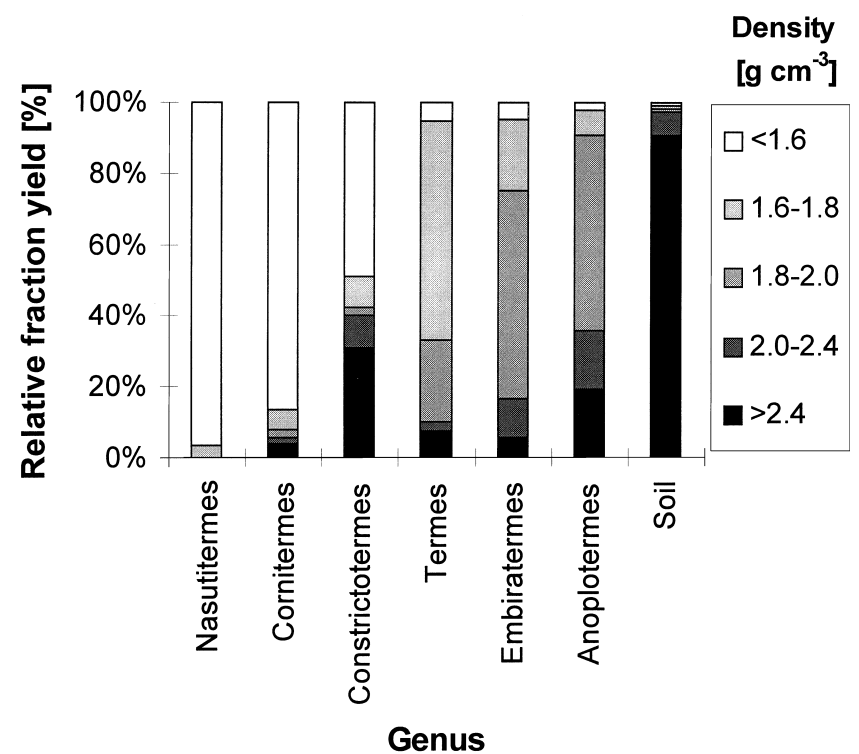

Fig. 1. Material distribution among density fractions in soil and inner nest wall of termite nests.

ID, $0.33 \mu \mathrm{m}$ film thickness) and detected by a flame ionization detector. Ethylvanillin was added as internal standard to the sample prior to alkaline extraction, and phenylacetic acid was used as a second internal standard added before derivatization in order to determine the recoveries of ethylvanillin. If the recovery of ethylvanillin did not exceed $60 \%$, the result was discarded and measurement was repeated.

The sum of extractable vanillyl, syringyl and cinnamyl phenolic $\mathrm{CuO}$ oxidation products (VSC) is a relative measure of the total lignin concentration (Hedges and Mann, 1979; Kögel, 1986). To indicate an increased side chain oxidation of the remnant lignin, we calculated the ratios of acids to aldehydes of the vanillyl and syringyl structures, $(\mathrm{ac} / \mathrm{al})_{\mathrm{V}, \mathrm{S}}$. These ratios increase with increasing lignin decomposition, while those of the syringyl-to-vanilllyl structural units (S/V) usually decline (Ertel and Hedges, 1984; Kögel, 1986). There- fore, both the $(\mathrm{ac} / \mathrm{al})_{\mathrm{V}, \mathrm{S}}$ and $\mathrm{S} / \mathrm{V}$ ratios are indicators of the degree of lignin decomposition.

\subsection{Statistical analyses}

For comparison of the fraction yields among the samples, we treated the six termite genera and the soils as a first independent factor and the five fractions as a second independent factor in a respective two-factorial $(7 \times 5)$-ANOVA (Statsoft, 1995). In doing so, we gave up the 'paired character' of our soil and termite samples, in order to increase the robustness of the test. Differences among means were tested by contrast analyses. The discussion of differences in nest properties among the studied genera was based on a grouping of the nests according to the two major feeding guilds $(N=2 \times 3)$. Interpretation of differences between individual bulk nests was based upon differences due to non-overlapping ranges of analysis.

It should be noted that the nests of Nasutitermes did not contain any heavy particles. Hence, respective fraction yields were set zero in the earlier A2 $(7 \times 5)$ ANOVA. However, due to the lack of these fractions, there were no data for lignin characters in the heavy fractions of Nasutitermes nests. Setting the lignin characters to zero as well would result in an undesired shift of arithmetic means and variances. Hence, we did not use the $(7 \times 5)$ ANOVA for the comparison of lignin characters among fractions outlined in Fig. 2. Here, the intention was to compare the average difference in lignin characters of density particles in termite nests with those of the soils, and we statistically only differentiated between the two groups 'termite nests' and 'soil'. Hence, the data of Fig. 2 were evaluated with a two-factorial $(2 \times 5)$ ANOVA. Lack of lignin data in the heavy particles of Nasutitermes nests thus resulted only in a reduction of the total sample size.

\section{Results}

The results from density fractionation showed that nests

Table 1

Concentration of $\mathrm{C}$ and lignin-derived phenols (VSC) and ratios of $\mathrm{C} / \mathrm{N}$, vanillic acid/vanillin ([ac/al $\left.]_{\mathrm{V}}\right)$, syringic acid/syringaldehyde ([ac/al $\left.]_{\mathrm{S}}\right)$, syringyl/ vanillyl structural units (S/V) and cinnamyl/vanillyl structural units $(\mathrm{C} / \mathrm{V})$ of the samples used in the study (standard errors are given in parentheses)

\begin{tabular}{|c|c|c|c|c|c|c|c|c|}
\hline Sample $^{a}$ & Feeding biology (assumed) & $\mathrm{C}\left(\mathrm{g} \mathrm{kg}^{-1}\right)$ & $\mathrm{C} / \mathrm{N}$ & $\begin{array}{l}\text { VSC } \\
\left(\mathrm{g} \mathrm{kg}^{-1} \mathrm{C}\right)\end{array}$ & $(\mathrm{ac} / \mathrm{al})_{\mathrm{V}}$ & $(\mathrm{ac} / \mathrm{al})_{\mathrm{S}}$ & $\mathrm{S} / \mathrm{V}$ & $\mathrm{C} / \mathrm{V}$ \\
\hline \multicolumn{9}{|l|}{ Termite mound } \\
\hline Nasutitermes sp. & Wood & $495(10)$ & $51(9)$ & $225(23)$ & $0.38(0.01)$ & $0.19(0.00)$ & $1.52(0.08)$ & $0.04(0.00)$ \\
\hline Cornitermes sp. & Wood & $384(15)$ & $22(2)$ & $85(8)$ & $0.37(0.01)$ & $0.36(0.02)$ & $1.04(0.17)$ & $0.10(0.00)$ \\
\hline Constrictotermes sp. & Lichen, wood & $303(22)$ & $18(1)$ & $13(1)$ & $0.33(0.05)$ & $0.47(0.10)$ & $0.75(0.07)$ & $0.29(0.02)$ \\
\hline Termes sp. & Soil + wood & $234(32)$ & $27(2)$ & $112(11)$ & $0.32(0.09)$ & $0.36(0.01)$ & $0.71(0.02)$ & $0.06(0.00)$ \\
\hline Embiratermes sp. & Soil + wood & $195(1)$ & $18(0)$ & $68(6)$ & $0.40(0.06)$ & $0.44(0.02)$ & $0.71(0.05)$ & $0.08(0.00)$ \\
\hline Anoplotermes sp. & Soil + wood & $168(15)$ & $16(1)$ & $43(7)$ & $0.38(0.04)$ & $0.47(0.01)$ & $0.72(0.02)$ & $0.15(0.01)$ \\
\hline \multicolumn{9}{|l|}{ Potential food } \\
\hline Wood & - & $476(2)$ & $94(13)$ & $124(10)$ & $0.15(0.04)$ & $0.12(0.03)$ & $2.96(0.54)$ & $0.09(0.01)$ \\
\hline Microepiphytes & - & $461(9)$ & $28(6)$ & $33(11)$ & $0.33(0.12)$ & $0.35(0.05)$ & $1.30(0.28)$ & $0.40(0.06)$ \\
\hline Ferralsol $(0-10 \mathrm{~cm})$ & - & $23(4)$ & $12(1)$ & $22(3)$ & $0.45(0.09)$ & $0.55(0.08)$ & $0.71(0.03)$ & $0.26(0.03)$ \\
\hline
\end{tabular}

\footnotetext{
${ }^{\mathrm{a}} n=2$ for the nests, $n=3$ for the lichen samples; $n=6$ for soil and wood samples.
} 


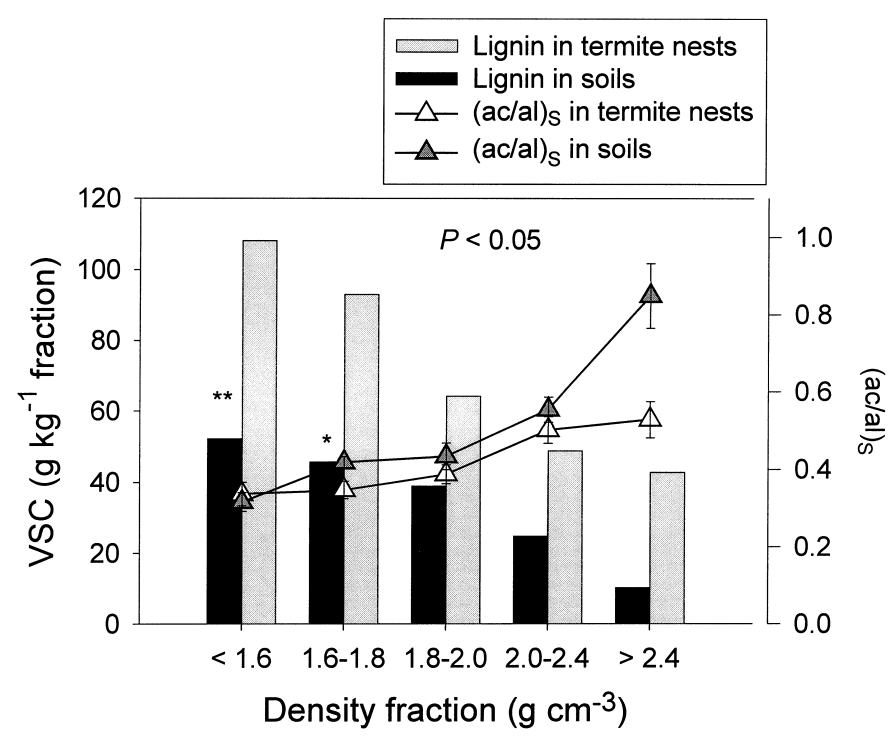

Fig. 2. Concentrations of lignin-derived phenols (VSC) and acid-to-aldehyde ratios of the syringyl structural units ([ac/al $\left.]_{\mathrm{S}}\right)$ in density fractions of soil and termite nest samples (averages from all samples). The asterisks ' $*$ ' and ' $* *$ ' indicate significant differences between soil and nest samples at the $P<0.05$ and $<0.01$ level of probability, respectively.

of different termite genera had a different density composition (Fig. 1;P<0.05). The nests of the wood-feeding genera Nasutitermes and Cornitermes were dominantly made of light fraction material. Light fraction material was negligible in nests of the soil/wood-interface feeding genera Termes, Embiratermes, and Anoplotermes. Within this feeding guild, the proportions of the $>2.0 \mathrm{~g} \mathrm{~cm}^{-3}$ density fractions (they contain the mineral material) also significantly differed $(P<0.05)$ and increased in the sequence Termes $\leq$ Embiratermes $<$ Anoplotermes $(<$ soil). Nests of Constrictotermes comprised both high proportions of light and of heavy material with little material in the intermediate density range (Fig. 1). Although the density composition among the different termite genera was highly variable, the nests of the soil/wood-interface feeding guilds contained consistently higher proportions of heavy material than the nests of the three other termites genera $(P<0.05)$.

Carbon and nitrogen analysis confirmed the different properties in the nests of different termite genera. The carbon contents and $\mathrm{C} / \mathrm{N}$ ratios were significantly lower in the nests of the soil/wood-interface feeding genera compared to the non-soil feeding guilds $(P<0.05$; Table 1). There was no pronounced difference in organic $C$ between the different nest parts (Amelung et al., 1998). Compared with the topsoil, the inner nest wall was enriched with $\mathrm{C}$ and $\mathrm{N}$ by a factor of $6-18$ and $4-5$, respectively (Table 1).

We determined lignin-derived phenols as a molecular marker for plant tissue in the samples. The lignin content relative to carbon in soil was one order of magnitude below that in the wood (Table 1). Nevertheless, the soil-dwelling termites did not have significantly lower lignin concentrations in their nests than the wood-feeding genera. Instead, there was a considerable variation in the lignin characteris- tics among the nests within the two respective feeding guilds (Table 1):

(a) Both the wood-feeding termites Nasutitermes spp. and Cornitermes spp. had highest $\mathrm{C}$ contents in their nests that, however, clearly differed in VSC concentrations. In addition, lignin in the nests of Cornitermes sp. was changed more by microorganisms, as indicated by higher $(\mathrm{ac} / \mathrm{al})_{\mathrm{S}}$ and lower S/V ratios, and slightly enriched with cinnamyl structural units compared with that of Nasutitermes nests.

(b) The soil/wood-interface feeding termites had $\mathrm{C}$ contents and VSC concentrations in their nests that both decreased in the order Termes sp. > Embiratermes sp. > Anoplotermes sp. As soil lignin was more oxidized than lignin in wood, $(\mathrm{ac} / \mathrm{al})_{\mathrm{V}, \mathrm{S}}$ ratios increased in the same order (not significant for the nests of Embira- and Anoplotermes sp.). As soil lignin had higher $\mathrm{C} / \mathrm{V}$ ratios than lignin in wood, the $\mathrm{C} / \mathrm{V}$ ratios also increased in the same direction.

(c) The nests of $C$. cavifrons were high in $\mathrm{C}$ but poor in lignin. This lignin was rich in cinnamyl $\mathrm{C}(\mathrm{C} / \mathrm{V}=0.29)$, as was that of lichens.

To reconcile these findings with those from density fractionation, we determined lignin-derived phenols in the density fractions (Fig. 2). The results showed that the heavier fractions from both soil and nests have lower VSC concentrations than the lighter fractions. Increasing (ac/ al $)_{\mathrm{V}, \mathrm{S}}$ ratios with increasing density $(P<0.05)$ indicated that this was due to increasing lignin-decomposition. Due to the high lignin concentrations in the light fractions, there was a negative correlation between the proportion of heavy material $\left(\geq 2.0 \mathrm{~g} \mathrm{~cm}^{-3}\right)$ in the nests with the total 
concentration of lignin-derived phenols (in $\mathrm{g} \mathrm{kg}^{-1}$ sample) in the nests $(r=-0.82, P<0.001 ; n=12)$. As a result, termites having little light material in their nests, such as those of the soil/wood-interface feeding guild (Termes, Embiratermes, Anoplotermes), also had little lignin in their nests, the nests of Constrictotermes being an exception.

\section{Discussion}

Soil minerals are unlikely to change their density during the gut passage of a termite. Termite mounds consist highly of excreta, and as soil particles are heavy in nature, increased feeding on soil will result in a higher proportion of heavy particles in the nest. Hence, the nests of the soil/ wood-interface feeders (Termes, Embiratermes, Anoplotermes) contained significant portions of heavy particles while those of the xylophagous genera (Nasutitermes, Cornitermes) did not. Increasing portions of heavy particles in the order Termes $\leq$ Embiratermes $<$ Anoplotermes could thus be seen as an indicator of increased soil-feeding and hence further specialization of feeding habits within this soil/wood-interface feeding guild.

The nest material of the soil/wood-interface feeders also contained a significant amount of material in the intermediate density range $\left(1.6-2.0 \mathrm{~g} \mathrm{~cm}^{-3}\right)$ that was not found in the potential food sources. We assume that this material was formed during nest construction. Its chemical properties ( $\mathrm{C} / \mathrm{N}$ ratio, lignin characteristics) suggest that it comprises an intimate mixture of soil and wood residues, as could have been formed during the passage through the gut of the soil/ wood-interface feeding termites genera. Earthworms casts also have densities of $1.6-2.0 \mathrm{~g} \mathrm{~cm}^{-3}$ (Beudert, 1988). There was very little material of this density range in the nests of $C$. cavifrons, which showed a bimodal material distribution among fractions (Fig. 1). We deduce that the soil particles in these nests had hardly passed the termite gut, i.e. that soil was only transported and not consumed by C. cavifrons. This reflects that $C$. cavifrons is not a soil/ wood-interface feeder. This species was observed carrying soil particles with its mandibles to the nest (Martius et al., 2000).

The particles of different density have different chemical compositions and lignin characteristics (Fig. 2). Hence, increased incorporation of heavy soil particles into the nests alters its chemistry: the $\mathrm{C}$ concentration, the $\mathrm{C}$ normalized lignin concentration and the $\mathrm{C} / \mathrm{N}$ ratio are lowered as soil feeding increases in the order Termes $<$ Embiratermes $<$ Anoplotermes. Changes in lignin content do therefore not primarily occur in the nest but reflect selection of soil material with lower lignin concentrations and higher (ac/al) $)_{\mathrm{S}}$ and $\mathrm{C} / \mathrm{V}$ ratios (Table 1; see also Cookson, 1992).

Termites are unable to digest lignin on a significant scale (Cookson, 1987; Pasti et al., 1990; Kuhnigk et al., 1994), and lignin in the nest material resists degradation (Cookson,
1992). Thus, the nest material may be richer in lignin than the food source. This was evident in the nests of woodfeeding Nasutitermes spp., where higher VSC concentrations $\left(\mathrm{g} \mathrm{kg}^{-1} \mathrm{C}\right)$ were found than in the wood (Table 1). Also the lower acid-to-aldehyde ratios in the heavy fraction of the termite nests (Fig. 2) rather indicate a preservation mechanism of fresh lignin than an increased lignin decay. The determination of the lignin concentration therefore allows identification of a feeding specialization within each feeding guild. Increasing lignin contents and decreasing $\mathrm{C} / \mathrm{V}$ ratios in the order Anoplotermes $<$ Embiratermes $<$ Termes indicated an increasing wood feeding, i.e. further specialization of feeding habits within the soil/wood-interface feeder guild.

The specialization within a major feeding guild was also evident within the guild of the plant feeders, among which the proportion of lignin from non-woody sources (indicated by lower lignin content and higher $\mathrm{C} / \mathrm{V}$ ratio) increased in the order Nasutitermes $<$ Cornitermes $<$ Constrictotermes. No data suggest that the $\mathrm{C} / \mathrm{V}$ ratio is greatly altered during organic matter decomposition in the terrestrial environment, and we therefore suggest that these genera were specialized in the selection of their food plants. Nasutitermes fed on woody material, rich in lignin, while Cornitermes probably accumulated plant residues from the forest floor, which are richer in Cinnamyl-C, in their nests. While nests of Nasutitermes commonly occurred at 2-20 m height on the tree trunk (Martius, 1994), those of Cornitermes were epi/endogeic down to $\leq 1 \mathrm{~m}$ soil depth. The suggested differentiation in food selection within this feeding guild thus seems to be very plausible. The relatively high $\mathrm{C} / \mathrm{V}$ ratio in the nests of C. cavifrons is consistent with observations that this genus feeds on organic matter other than wood, namely microepiphytes (lichens, mosses, etc. Araujo, 1970; Martius et al., 2000).

In summary, combining a density fractionation with the determination of $\mathrm{C}$ and lignin-derived phenols in termite nests allowed a classification of the respective termite nests with respect to their food incorporation. Differences in nest properties between species greatly exceeded differences between nests of individual species. Species-specificity of nest architecture was often reported (see e.g. Schmidt, 1955), and our findings indicate that it extends into the chemical composition of the termite nest. In the present study, nest properties suggested a shift from wood to soil food incorporation in the order Nasutitermes $>$ Cornitermes $>$ Termes $>$ Embiratermes $>$ Anoplotermes, while the nests of Constrictotermes were mainly characterized by the existence of microepiphyte residues.

\section{Conclusions}

Compared to the surrounding soil, termite nests were significantly enriched in soil organic matter. The degree of this enrichment depended on the feeding guild. 
Xylophagous termites significantly accumulated light fraction SOM, while nests of soil/wood-interface feeders were lower in $\mathrm{C}$ and contained more heavy fraction SOM. The light fraction $\mathrm{C}$ was enriched with little altered lignin while lignin in the heavy fractions showed evidence of advanced stages of alteration. The lignin characteristics, however, exhibited a considerable variation among the nest properties within each feeding guild, which coincided with proportions of lignin from woody or non-woody plant fragments. Resolving organism-specialized food selections, e.g. by compound specific isotope determinations in termite gut, stable nest parts and potential food sources, might thus warrant further attention.

\section{Acknowledgements}

We thank D. Ulbrich for his support during field sampling, and Ms U. Kueper for contributing to the analyses, and the anonymous reviewers for their constructive comments. The work was funded by the German Science Foundation (projects DFG Ze 154/35-1, Ma 1276/ 5-1).

\section{References}

Amelung, W., Zech, W., 1999. Minimisation of organic matter disruption during particle-size fractionation of grassland epipedons. Geoderma 92, $73-85$.

Amelung, W., Flach, K.-W., Zech, W., 1997. Climatic effects on soil organic matter composition of the Great Plains. Soil Science Society of American Journal 61, 115-123.

Amelung, W., Martius, C., Garcia, M., Kueper, U., Ullbrich, D., Zech, W., 1998. Organic matter in termite mounds of an Amazonian rain forest, Brazil. In: Lieberei, R., Voß, K., Bianchi, H. (Eds.), Proceedings of the Third SHIFT-Workshop Manaus, March 15-19, 1998, GKSSForschungszentrum GmbH, Geesthacht, Germany, pp. 493-496.

Araujo, R.L., 1970. Termites of the Neotropical region. In: Krishna, K., Weesner, F.M. (Eds.). Biology of Termites. Academic Press, London, pp. 527-576.

Beudert, G., 1988. Mikromorphologische, naßchemische und ${ }^{13}$ C-CPMASNMR-spektroskopische Kennzeichnung der organischen Bodensubstanz von Waldhumusprofilen nach Dichtefraktionierung. Bayreuther Bodenkundliche Berichte, Band 8.

Bignell, D.E., Eggleton, P., 2000. Termites in ecosystems. In: Abe, T., Bignell, D.E., Higashi, M. (Eds.). Termites: Evolution, Sociality, Symbiosis, Ecology. Kluwer Academic Publishers, Dordrecht, pp. 363-387.

Boutton, T.W., Arshad, M.A., Tieszen, L.L., 1983. Stable isotope analyses of termite food habits in East African grasslands. Oecologia 59, 1-6.

Bustamante, N.C.R., Martius, C., 1998. Nutritional preference of woodfeeding termites inhabiting floodplain forests of the Amazon river, Brazil. Acta Amazonica 28, 301-307.

Christensen, B.T., 1992. Physical fractionation of soil and organic matter in primary particle size and density separates. Advances in Soil Science 20, 1-90.
Cookson, L.J., 1987. ${ }^{14} \mathrm{C}$-lignin degradation by three Australian termite species (Isoptera: Mastotermitidae Rhinotermitidae, Termitidae). Wood Science and Technology 21, 11-25.

Cookson, L.J., 1992. Studies of lignin degradation in mound material of the termite Nasutitermes exitosius. Australian Journal of Soil Research 30, 189-193.

Deligne, J., 1966. Caractères adaptifs au régime alimentaire dans la mandibule des termites (Insectes Isoptères). Comptes Rendus des Séances de l' Academie des Sciences, Paris 263, 1323-1325.

Ertel, J.R., Hedges, J.I., 1984. The lignin component of humic substances: Distribution among soil and sedimentary humic, fulvic and base insoluble fractions. Geochimica Cosmochimica Acta 48, 2065-2074.

FAO-UNESCO, 1997. Soil Map of the World, Revised Legend. ISRIC, Wageningen.

Hedges, J.I., Ertel, J.R., 1982. Characterization of lignin by gas capillary chromatography of cupric oxide products. Analytical Chemistry 54, 174-178.

Hedges, J.I., Mann, D.C., 1979. The characterization of plant tissues by their lignin oxidation products. Geochimica Cosmochimica Acta 43, 1803-1807.

Kögel, I., 1986. Estimation and decomposition pattern of the lignin component in forest soils. Soil Biology and Biochemistry 18, 589-594.

Kuhnigk, T., Borst, E.-M., Ritter, A., Kämpfer, P., Graf, A., Hertel, H., König, H., 1994. Degradation of lignin monomers by the hindgut flora of xylophagous termites system. Applied Microbiology 17, 76-85.

Ladd, J.N., Foster, R.C., Skjemstad, J.O., 1993. Soil structure: carbon and nitrogen metabolism. Geoderma 56, 401-434.

Lee, K.E., Wood, T.G., 1971. Termites and Soil. Academic Press, London.

Lepage, M., Abbadie, L., Mariotti, A., 1993. Food habits of sympatric termites (Isoptera, Macrotermitinae) as determined by stable isotope analysis in a Guinean savanna (Laamto, Cote d'Ivoire). Journal of Tropical Ecology 9, 303-311.

Martius, C., 1994. Diversity and ecology of termites in Amazonian forests. Pedobiologia 38, 407-428.

Martius, C., Amelung, W., Garcia, M.V.B., 2000. The Amazonian forest termite Constrictotermes cavifrons feeds on microepiphytes. Sociobiology 35, 379-383.

North, P.F., 1976. Towards an absolute measurement of soil structural stability using ultrasound. Journal of Soil Science 27, 451-459.

Pasti, M.B., Pometto III, A.L., Nuti, M.P., Crawford, D.L., 1990. Ligninsolubilizing ability of actinomycetes isolated from termite (Termitidae) gut. Applied Environmental Microbiology 56, 2213-2218.

Schmidt, R.S., 1955. Termite (Apicotermes) nests-important ethological material. Behavior 8, 344-356.

Sleaford, F., Bignell, D.E., Eggleton, P., 1996. A pilot analysis of gut contents in termites from the Mablmayo Forest Reserve Cameroon. Ecological Entomology 21, 279-288.

Spain, A.V., Redell, P., 1996. $\delta^{13} \mathrm{C}$ values of selected termites (Isoptera) and termite modified materials. Soil Biology and Biochemistry 28 , $1585-1593$.

StatSoft, Inc., 1995. Statistica for Windows 5.1 [Computer programhandbook]. Tulsa, OK, USA.

Tayasu, I., Abe, T., Eggleton, P., Bignell, D.E., 1997. Nitrogen and carbon isotope ratios in termites: an indicator of trophic habit along the gradient from wood-feeding to soil-feeding. Ecological Entomology 22, 343-351.

Varma, A., Kolli, B.K., Paul, J., Saxena, S., König, H., 1994. Lignocellulose degradation by microorganisms from termite hills and termite guts: a survey on the present state of art. FEMS Microbiology Reviews 15, 928 . 